Type of the Paper (Article, Review, Communication, etc.)

\title{
Assessing Impacts of Drought on Agriculture and Food Security in the Baribo Basin, Cambodia
}

\author{
Kimhuy Sok ${ }^{1}$, Supattra Visessri ${ }^{1,2, *}$ and Sokchhay Heng ${ }^{3}$ \\ 1 Department of Water Resources Engineering, Faculty of Engineering, Chulalongkorn University, Bangkok, \\ Thailand; 6171452421@student.chula.ac.th; supattra.vi@chula.ac.th \\ 2 Disaster and Risk Management Information Systems Research Unit, Chulalongkorn University, Bangkok, \\ Thailand; supattra.vi@chula.ac.th \\ 3 Faculty of Hydrology and Water Resources Engineering, Institute of Technology of Cambodia, Phnom \\ Penh, Cambodia; heng_sokchhay@yahoo.com \\ * Correspondence: supattra.vi@chula.ac.th
}

\begin{abstract}
Rice production in the Tonle Sap basin is one of the main drivers for economic and social development in Cambodia. The Tonle Sap basin has experienced many different forms of disasters while more attention has been drawn to drought disaster. The objective of this study is to assess the impacts of drought on agriculture and food security through a case study of the Baribo basin, a sub-basin of Tonle Sap basin, Cambodia. Ground observations and satellite-based products were used for drought assessment from 1985 to 2008 which was the period with relatively good data quality. The Standardized Precipitation Index (SPI) and Standard Vegetation Index (SVI) were selected for meteorological and agricultural droughts assessment, correspondingly. Both SPI and SVI consistently suggested that drought is a major natural hazard causing food insecurity in the target basin. The highest drought intensity (DI) and severity (DS) occurred between 1993-1994 and the longest drought duration (DD) occurred between 2002 and 2006. The most severe damage to rice production was in 2004, affecting about $46 \%$ of the total cultivated area. The analysis showed that drought duration had a strong relationship with the affected area growing rice as well as food insecurity in the Tonle Sap basin.
\end{abstract}

Keywords: Tonle Sap; meteorological drought; agricultural drought; drought index; drought duration

\section{Introduction}

Food security is a complex, multifaceted, challenging and politically driven global and local issue [1-3]. Food security defined as a situation when all people, at all times, have physical, social and economic access to sufficient, safe and nutritious food that meets their dietary needs and food preferences for an active healthy life [4-5]. Many studies showed that the global food demand over the past half-century has grown ahead of supply, owing to the increase in the world population [6-11]. At the same time, many different forms of natural disasters have threatened food security in agricultural countries such as Cambodia $[2,6-7,12-13]$ where nearly one third of farmers cultivate rice as a primary crop through traditional farming practices [14]. Realizing the threats to food security, the Royal Government of Cambodia (RGC) from the third to sixth legislatures (2004 to present), has applied a "Rectangular Strategies" policy [15]. One of the RGC's main strategies emphasizes managing water resources and natural disasters. Improving water management and increasing agricultural production have been considered as one of the main priorities for developing the country.

The Tonle Sap basin is a major agricultural region covering about $44 \%$ of the country's territory and accommodating about $32 \%$ of the total population [16]. It has experienced many different forms of natural disasters including drought [17]. Drought is a natural disaster that develops over a relatively long period [18]. Drought can cause a 
reduction in agricultural yield and food insecurity. Ministry of Environment (MoE) of Cambodia estimated that there was a $20 \%$ reduction in Gross Domestic Product (GDP) in the agricultural sector and that $54 \%$ of the total population suffered from drought in 1998 and 2002. A severe drought damaged $3000 \mathrm{~km}^{2}$ of rice paddy fields, leading to an $82 \%$ loss of the potential rice production in 2004. Approximately 12 million USD were spent in combatting another severe drought in 2009 [19]. The assessment of drought characteristics such as drought frequency, duration, severity, intensity and distribution is therefore needed to improve understanding of the drought process and identify sensitive agricultural areas which are subject to drought [20-21]. The findings from this study support the implementation of the RGC's policy and the United Nations Sustainable Development Goals (https:sustainabledevelopment.un.org/focussdgs.html).

Droughts are commonly categorized as meteorological, agricultural and hydrological droughts. In this study, meteorological and agricultural droughts were assessed but not hydrological drought because it is less relevant to the rice production in Cambodia. Meteorological drought refers to the deficiency of rainfall and its calculation mainly relies on rainfall and temperature. Meteorological drought leads to insufficiency of soil moisture content and subsequently results in agricultural drought, which generally refers to a period when the crops reach wilting point, causing crop failures [22]. The drought index or indicator is widely used to assess each type of drought [23]. Drought indices are quantitative measures using key raw climatological variables or indicators to determine characteristics of drought and to transform them into a single numerical value which is more convenient to use than the raw indicator [24]. Two primary sources of key raw data are ground observation and satellite-based products. However, ground observation data such as soil moisture and evapotranspiration for indicating agricultural drought are scarce. With the development of new technology during the past decades, satellite data plays an essential role in assessing the agricultural droughts. Many satellite-based agricultural drought indices have been developed to overcome the limitation of indices using ground observation data. In our study, the Standardized Precipitation Index (SPI), mainly relied on the precipitation, was employed to assess the meteorological drought; and Standard Vegetation Index (SVI), mainly relied on Normalized Difference Vegetation Index (NDVI), was used to evaluate agricultural drought. The objective of this study is to assess the impacts of drought on agriculture and food security through a case study of the Baribo basin in Cambodia.

\section{Study Area}

The Baribo basin is located between latitudes $11^{\circ} 30^{\prime} 00^{\prime \prime} \mathrm{N}-12^{\circ} 42^{\prime} 00^{\prime \prime} \mathrm{N}$ and longitudes $104^{\circ} 00^{\prime} 00^{\prime \prime} \mathrm{E}-104^{\circ} 57^{\prime} 00^{\prime \prime} \mathrm{E}$ (Figure. 1). The size of the basin is 7,092 $\mathrm{km}^{2}$. The elevation varies from 0 to 1,800 msl (Meter above mean Sea Level). Many small reaches flow directly from the west to the east into the Tonle Sap Great Lake which is divided into three main regions, namely Northern regions $\left(1,091 \mathrm{~km}^{2}\right)$, Central region $\left(2,995 \mathrm{~km}^{2}\right)$ and Southern region $\left(3006 \mathrm{~km}^{2}\right)$. According to Sok et al. [25], the major land use in the Baribo basin is forest, accounting for $63.2 \%$. Agriculture is mainly distributed in the eastern part of the basin and occupies $34.4 \%$. Over $95 \%$ of the agricultural area is rice paddy. The rest of the basin is an urban area and water body. The annual rainfall in the Baribo basin is governed mainly by tropical monsoons and isolated tropical cyclones [26]. The variation of the rainfall over the basin area depends on topography [27]. The annual rainfall of the Baribo basin varies from 1,040 $\mathrm{mm}$ in the south, with a low-gradient and low-relief landscape, to $1525 \mathrm{~mm}$ in the lower north of the basin adjacent to the Tonle Sap Great Lake [28]. 


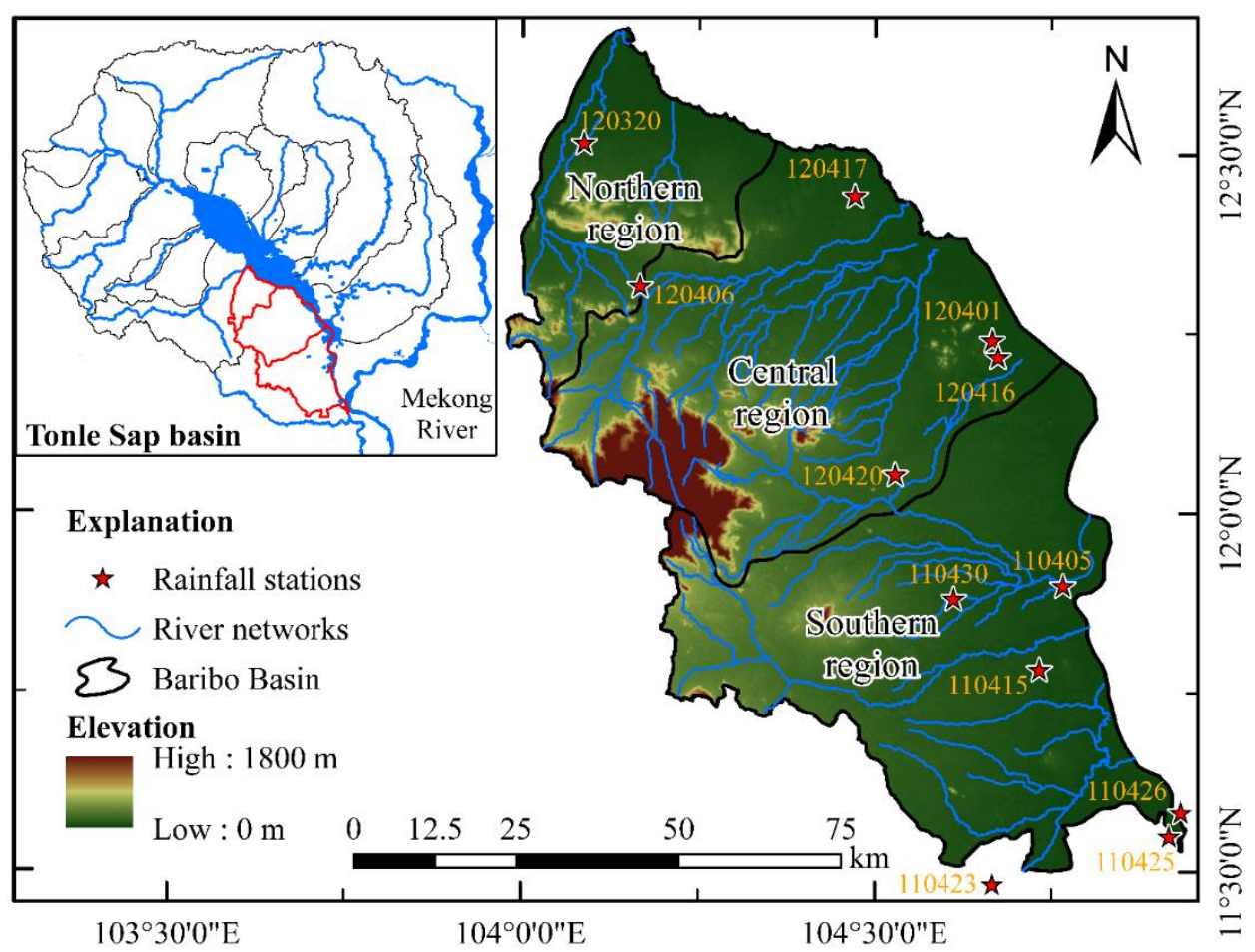

Figure. 1. General characteristics of the Baribo basin, a sub-basin of Tonle Sap basin.

Three types of rice varieties are commonly grown in Cambodia: long (LD), medium (MD), and early duration (ED). The cropping period for $L D, M D$, and ED rice varieties normally takes six, four and three months, respectively (Figure 2). The LD rice is grown in the rainfed area. The seeding period is from mid-May to mid-July and the harvest is between mid-October and mid-December. The MD rice is grown in the wet season between mid-August to mid-December. The ED rice has recently been introduced to Cambodia's farming system because it has a shorter cropping period, needs less water and generates higher income than the LD rice. It can be harvested about three months after seeding and can be grown up to three times per year. The ED rice varieties are cultivated between (1) early January and late March (ED1) when farmers use standing water and residual soil moisture which can be supplemented by irrigation; (2) early May and early August (ED2) when farmers use early wet season rains before harvesting in the short period of rainfall absence during the wet season or the shift of the Inter-Tropical Convergence Zone (ITCZ); and (3) early September and mid-December (ED3) when farmers rely heavily on rainfall in the wet season and the harvest period coincides with LD and MD rice varieties. The proportions of the $\mathrm{LD}, \mathrm{MD}$, and ED rice by area planted are approximately $20 \%, 40 \%$, and $33 \%$, respectively [19]. 

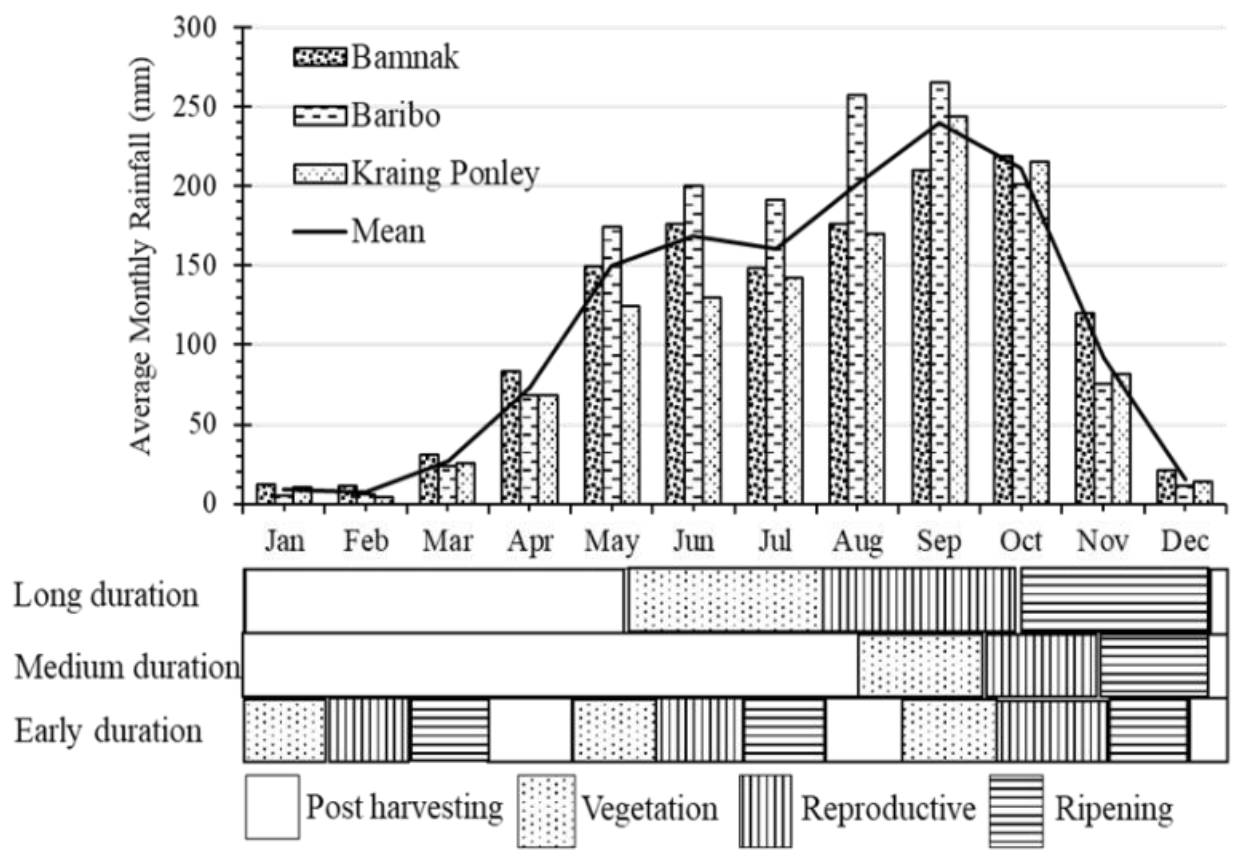

Figure. 2. Cropping patterns and monthly rainfall in the Baribo basin (reproduced with permission from Chhinh and Millington [19]).

\section{Materials and Methods}

The SPI and SVI were used in this study to assess meteorological and agricultural droughts, accordingly. These indices were calculated at 3- and 6-month timescales to match the cropping pattern of $\mathrm{LD}, \mathrm{MD}$, and ED rices and a 12-month timescale to assess the annual variation of rainfall and greenness density of the vegetation. The rainfall data from 12 stations located within or nearby the Baribo basin (Figure 1) were obtained from Ministry of Water Resources and Meteorology (MOWRAM). The Normalized Difference Vegetation Index (NDVI) data were downloaded from the National Oceanic and Atmospheric Administration (NOAA)'s website. Due to the ungauged nature of the basin, it is challenging to obtain sufficient number of gauges and record length that allow reliable analysis. Previous studies suggested that at least 20 years of record should be used for low flow or drought analysis [29-31]. The study period of 24 years between 1985 and 2008 was selected in this study because it was the period with relatively high number of gauges with long record and good data quality. The estimation of indices and analysis framework are explained in the following sections.

\subsection{Meteorological drought}

The SPI, developed by McKee et al. [32], is a widely used meteorological drought index [33] and only requires monthly rainfall as an input. The estimation is simple, involving probability distribution of monthly rainfall. In this study, Gamma distribution was tested and found to fit well with the observed rainfall data (Figure S1). The fit of Gamma distribution to monthly rainfall in Cambodia was supported by several previous studies $[19,28,34]$. The probability density function and cumulative density function of the Gamma distribution of the observed rainfall in each month (January to December) was firstly obtained and transformed to the standard normal random variable $\mathrm{Z}$ with the zero mean $(\overline{\mathrm{x}})$ and unit variance (s) using equation (1). For more details of the SPI calculations refer to McKee et al. [32]. The interpretation of the SPI values is the degree by which the observed rainfall anomaly deviates from the long-term mean. The SPI can reflect abnormally dry or wet conditions but cannot account for the effect of other climate variables 
such as temperature and evaporation. The classification of drought based on SPI value is shown in Table 1.

$$
\text { Z or SPI }=\frac{x_{i}-\bar{x}}{S}
$$

Table 1. Drought classification based on SPI values [34].

\begin{tabular}{cl}
\hline SPI value & Description \\
\hline Above 2.0 & Extremely wet \\
1.5 to 2.0 & Severely wet \\
1.0 to 1.5 & Moderately wet \\
-1.0 to 1.0 & Near normal \\
-1.5 to -1.0 & Moderately drought \\
-2.0 to -1.5 & Severely drought \\
Below -2.0 & Extremely drought \\
\hline
\end{tabular}

\subsection{Agricultural drought}

The SVI, developed by Peters et al. [35], is an index of agricultural drought. It indicates the failure or unhealthy condition of vegetation which may be caused by drought, flood, crop rotation and unseasonable coolness [35]. The input for calculating SVI is NDVI which represents the greenness density of the vegetation. The NDVI data can be downloaded from several satellites databases which are briefly listed here. The coarse resolution of NDVI ranging from $250 \mathrm{~m}$ to $1 \mathrm{~km}$ were recorded by SPOT-4's vegetation instrument from 1998 to the present and NASA's Moderate Resolution Imaging Spectrometer (MODIS) from 2000 to the present, respectively. Although new technology and modern instruments have been improved, the older Advanced Very High Resolution Radiometer (AVHRR) data with resolution of $5 \mathrm{~km}$ and available from $1981 \mathrm{up}$ to the present are still a vital and irreplaceable archive for historical land surface. Some studies such as Peters et al. [35] and Tian et al. [36] showed that NDVI obtained from AVHRR provided a good relationship with vegetation condition. Thus, the NDVI data calculated based on the AVHRR were selected for this study.

The NDVI date were accumulated over the time scales of interest and transformed to normal distribution with zero mean and unit variance. The SVI was then estimated, based on the cumulative distribution function of the NDVI as shown in equation (2) where $\mathrm{P}\left(\mathrm{Z}<\mathrm{z}_{\mathrm{i}}\right)$ is the probability with the random variable $\mathrm{Z}$ and $\mathrm{Z}_{\mathrm{i}}$ is a deviation of NDVI from the mean. The classification of vegetation's health condition based on SVI is shown in Table 2.

$$
\mathrm{SVI}=\mathrm{P}\left(\mathrm{Z}<\mathrm{z}_{\mathrm{i}}\right)
$$

Table 2. Vegetation's health condition classification based on SVI value [35].

\begin{tabular}{ll}
\hline SPI value & Description \\
\hline 0.00 to 0.05 & Very poor \\
0.05 to 0.25 & Poor \\
0.25 to 0.75 & Near normal \\
0.75 to 0.95 & Good \\
0.95 to 1.00 & Very good \\
\hline
\end{tabular}




\subsection{Theory of Runs (ToR)}

Theory of Runs (ToR) [37] is a statistical property of sequences applied to define drought characteristics, namely: drought event (DE), drought duration (DD), drought severity (DS) and drought intensity (DI). ToR has been used extensively for drought assessment [34, 37-38] since it explains a variety of aspects of drought through a simple graphic representation as shown in Figure S2. DE is a period in which the value of a drought index is consecutively lower than the critical threshold value. Once DE is identified, DD, DS and DI are subsequently obtained.

For SPI, the DE is a period where the SPI values are continuously below 0 with the lowest SPI value less than or equal to -1. For SVI, the DE is a period of poor vegetation condition, possibly caused by drought. The DE is identified when SVI is continuously below 0.5 with the lowest value less than or equal to 0.25 . The DD is the number of months in a DE. The DS is the summation of absolute values of the index in a DE. The DI can be defined in two ways: the absolute lowest value of the index (DI1); and the ratio between DS and DD in a DE (DI2).

\section{Results}

\subsection{Meteorological drought}

The meteorological drought was assessed using SPI at three different timescales ( 3,6 and 12 months). The analysis of SPI at 3 months (SPI3) and 6 months (SPI6) can be used to evaluate the seasonal variation of rainfall and the impact of drought on agriculture. The 12 month timescale (SPI12) can be used to monitor annual rainfall availability and variation.

\subsubsection{Temporal analysis of Standardized Precipitation Index}

The values of SPI3, SPI6, and SPI12 for the three regions located in the Baribo basin are shown in Error! Reference source not found.3. The regional average SPI in Figure 3 was computed using rainfall data from 12 stations and the Theissen polygon method. Figure 3 shows that SPI values generally range between -3 and 3 . There is a highly temporal fluctuation for SPI3 with alternating periods of dry and wet conditions. The SPI6 and SPI12 assessed drought on a longer timescale and had less fluctuation than SPI3. The drought events identified in the Northern and Southern regions were in 1989 and 1990 and in the entire Baribo basin in 1993 to 1994, 1997 and 2002 to 2006. The continuous wet period of the three regions occurred from 1996 to 1997 and 1999 to 2001 . The SPI values in the Northern region were generally lower than those of the other two regions. The lowest SPI values in the Northern region were found in 1990 and were equal to -2.44 (SPI3), -2.44 (SPI6), and -2.38 (SPI12). The drought in the three regions was longer and more frequent between 2002 and 2006 compared to the previous drought events. 


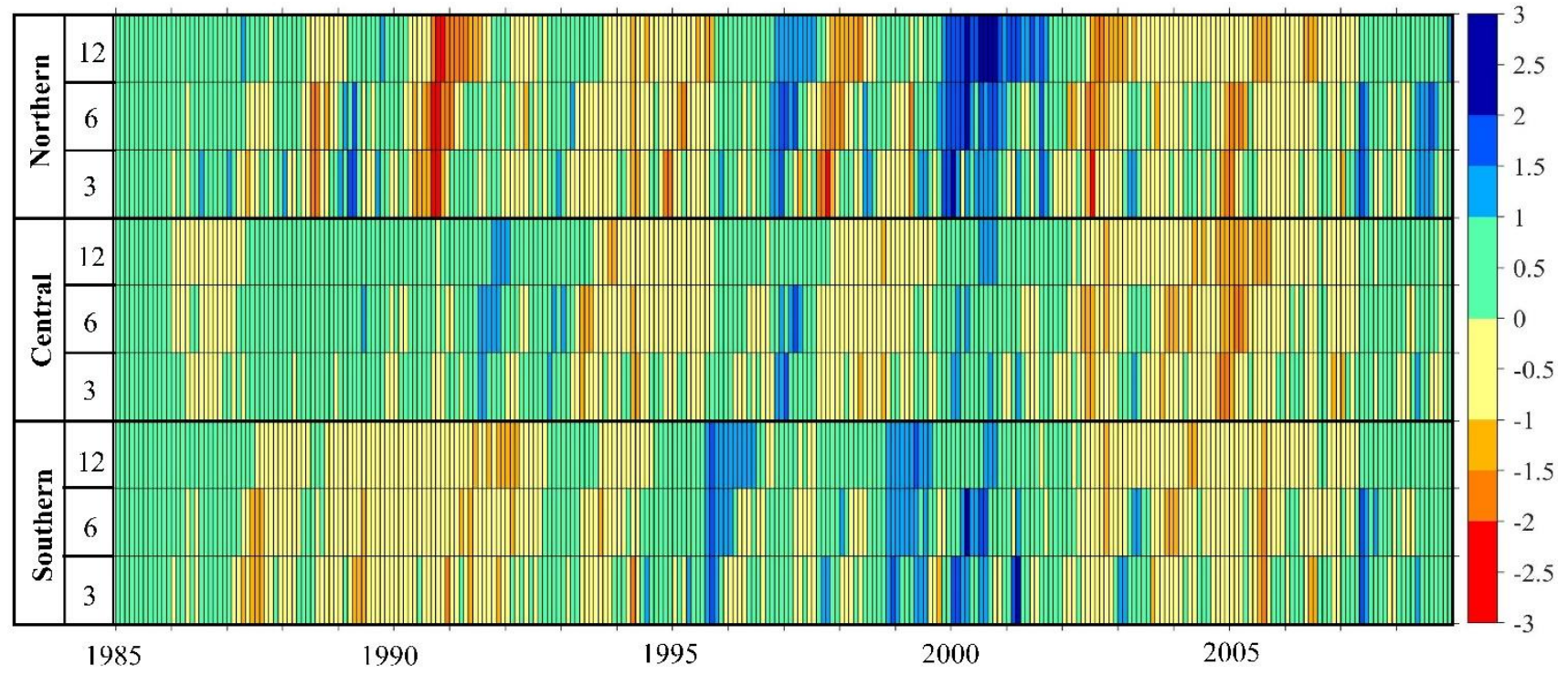

Figure. 3. Standardized Precipitation Index (SPI) values of the three regions between 1985 and 2008.

\subsubsection{Drought characterization by ToR for Standardized Precipitation Index}

Table S1 to Table S3 list the properties of each DE (drought event) in terms of DD (drought duration), DS (drought severity), DI1 and DI2 (drought intensity) at three timescales of the three regions using ToR. The results show that the DE decreased as the timescale increased. Droughts occurred most frequently in the Northern region, especially for SPI3 and SPI6 because of the high variation of rainfall in the wet and dry seasons. Similar values of $\mathrm{DE}$ were found for all regions showing a small variation of annual rainfall over the Baribo basin. The three timescales showed that the drought occurred in the Baribo basin mainly from 1990 to 1998 and 2002 to 2006.

As the timescale increased, the consecutive period with negative SPI increased. Table S1 to Table S3 indicate that the longest length of DD at the SPI3, SPI6, and SPI12 were 9, 17, and 59 in the Northern region, 13, 30 and 51 in the Central region, and 15, 47 and 51 in Southern region, respectively. These longest periods of drought occurred mostly between 2002 and 2006. The Southern region experienced the longest DD, followed by the Central region at SPI3 and SPI6. This could cause unfavorable societal and economic consequences. The longest drought duration was found in Northern region (59 months) when assessing using SPI12. The duration of drought covering several years has been found in this region as the rainfall is highly variable in the tropical zone. Similarly, Guo et al. [34] found that the longest DD in the Lower Mekong basin lasted about 38 months.

When considering the DS, the maximum DS was regularly found in the DE with the longest DD. The DS increased with a longer timescale. The most severe drought for the SPI3, SPI6, and SPI12 were 12.01, 17.83, and 43.03 in the Northern region, 10.77, 23.26, and 36.63 in the Central region, and 7.62, 28.19, and 31.41 in Southern region, respectively. The severity of the drought is variable across regions and the timescales.

For DI, the intensity of drought decreased over a long timescale. The most intense drought for all timescales was found in the Northern region. Based on Table 1, the values of DI1 $\geq 2$ suggest that extreme drought was common in the North while the drought in the other two regions is generally at moderate or severe category.

The Northern, Central, and Southern regions were subjected to drought but with different characteristics. When all the ToR parameters (DE, DD, DS, DI) were considered together, it appears that droughts in the Northern region were most intense and occurred most frequently but with short duration. Droughts in the Central and Southern regions were not as intense and frequent as in the North but lasted longer.

4.1.3. Impacts of droughts on cropping patterns by Standardized Precipitation Index 
Three months (March, July and November) of the rice ripening period as shown in Figure 2 were selected for assessing the impact of drought on rice production. Figure S3 and Figure S4 show SPI3 and SPI6 values in March, July and November from 1985 to 2008. SPI3 indicates the impact of drought on the ED rice varieties because it covers the variation of rainfall for the whole cropping period. For example, the SPI3 value in March was used the accumulation of rainfall from January to March in the computation, which covers the whole cropping period of ED1. SPI6 indicates the impact of drought on cropping for the rice varieties MD (four to five months) and LD (six months).

Figure S3 shows that the ED rice varieties in the Northern region were affected by more frequent and intense drought compared to the other two regions. Droughts usually occurred in July and November. July was particularly dry and November was the end of rainy season. The ED rice varieties in the three regions were less affected by drought in March. From 2002 to 2006, the ED rice varieties experienced more frequent droughts with higher intensity. Figure S4 shows that the impacts of drought on the rice varieties in the Northern region were higher than the Central and Southern regions. The negative value of SPI in November was found in five consecutive years in the three regions between 2002 and 2006. This suggested wide and prolonged impacts of drought on the rice varieties. It can cause a significant damage to the production of ED3, LD and MD rice varieties.

Referring to the analysis above, droughts caused serious damage to the three types of rice varieties between 2002 and 2006. Furthermore, droughts occurred in November more frequently in than March and July. Those droughts occurring in November caused more damage to agricultural production than those in March and July, since the three types of rice varieties (ED3, MD and LD) which are ripened in November, account for more than $60 \%$ of total annual rice production. Based on the SPI, drought is a major natural disaster which has led to food insecurity in Cambodia. Our result is parallel with the data reported by United Nations Development Programme (UNDP; http://camdi.ncdm.gov.kh); the drought was severely damaged the agricultural production in Kampong Chhang and Kampong Speu Provinces between 2002 and 2006 with a maximum affected area of 78,000 ha in 2004.

\subsection{Agricultural drought}

Agricultural droughts were assessed using SVI at three different timescales: 3 months, 6 months and 12 months. The analysis of SVI at 3months (SVI3) and 6 months (SVI6) were used to evaluate the seasonal variation of the vegetation's greenness density. The 12 month timescale (SVI12) played an essential role in monitoring the variation of annual greenness density of vegetation.

\subsubsection{Temporal Analysis of Standard Vegetation Index}

The values of SVI at 3, 6 and 12 month timescales are shown in Error! Reference source not found. 4 and more details of drought characteristics are provided in Table 2 . One of the most important indicators of SVI is that not only droughts but also floods and crop rotation caused poor vegetation conditions.

Error! Reference source not found. 4 shows that the vegetation conditions in the three regions had a high correlation with each other. Poor vegetation conditions were found from 1988 to 1989, 1992 to 1994, 1999 to 2001 and 2004 to 2006 . The slightly better conditions observed between 2004 and 2006 may have been due to improvements in agricultural management, adaptation and extended of the agricultural area that were implemented as a key policy of Cambodia's government from July 2004. The very poor vegetation (SVI < 0.05) conditions did not occur in the Northern region in any of the timescales. The poor vegetation condition of the long timescale started later but lasted longer than the short timescales. 


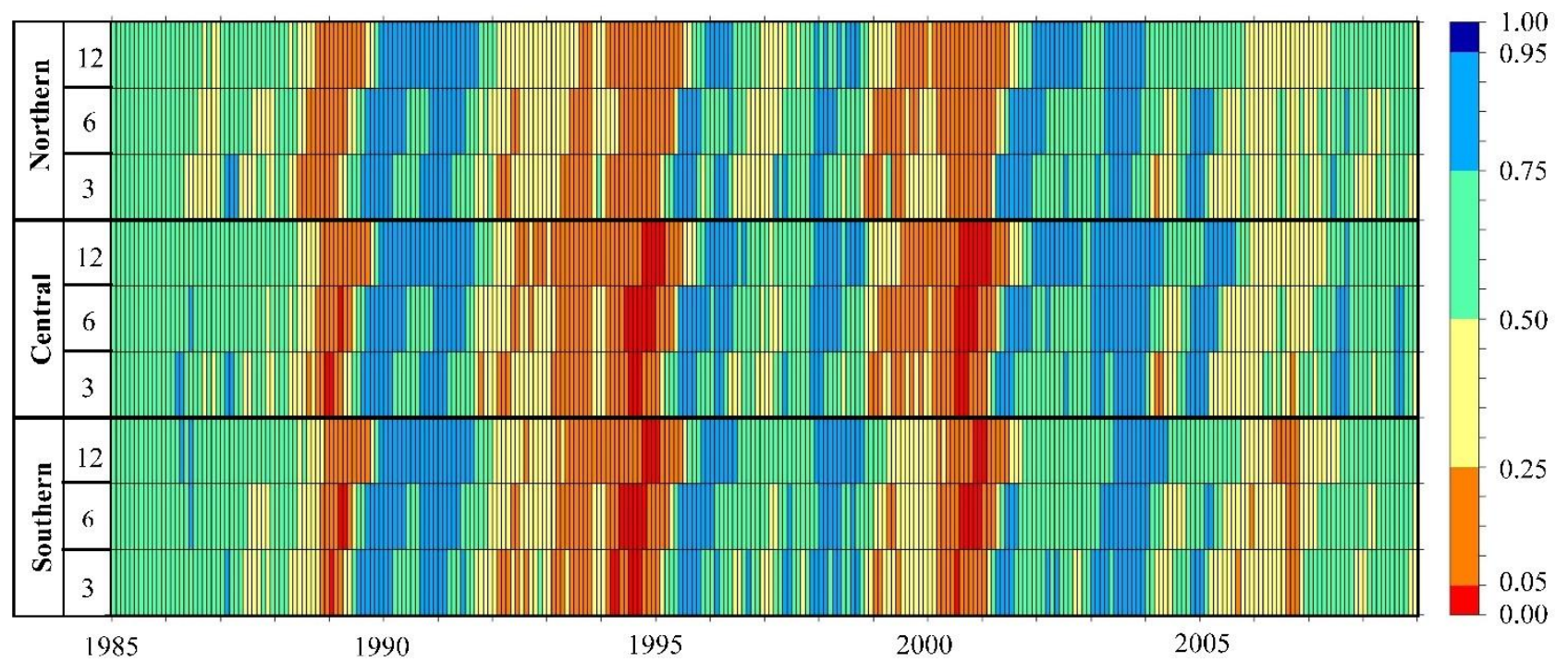

Figure. 4. Standard Vegetation Index (SVI) values of the three regions between 1985 and 2008

\subsubsection{Drought Characterization by ToR for Standard Vegetation Index}

Table S4 to Table S6 illustrate the properties of each DE (Drought Event) in terms of DD (Drought Duration), DS (Drought Severity), DI1 and DI2 (Drought Intensity) at three timescales in the three regions using ToR. The DE results indicated that the three regions for all timescales were comparable. Furthermore, DE did not change greatly from timescale to timescale. For example, the number of drought events at SVI3, SVI6, and SVI12 were 6, 3 and 3 in the Northern region, 5, 3 and 3 in the Central region and 5, 4 and 4 in the Southern region, respectively.

In the case of DD (Table S4 to Table S6), the three regions had a similar DD and it increased slightly from the shorter to longer timescales. The lengths of DD for all timescales in the Central region were comparable. In the Northern and Southern regions, the longest period of DD at SVI3 (DD = 23 and 28) was about two times lower than SVI6 (DD $=42$ and 41$)$ and SVI12 (DD = 43 and 43). The results also indicated that these three regions experienced the longest DD between 1992 and 1995.

From Table S4 to Table S6, the results indicated that the minimum DS occurred in the three regions at different timescales. The minimum DS was found in the Central region at SVI3 and SVI6 (DS = 1.3 and 2.46) and in the Southern region at SVI12 (DS =3.55). The lower value of SVI showed the low greenness density of the vegetation. It appears that the seasonal greenness density in the Central region was poorer than that of other two regions. However, the overall annual greenness density in the Southern region was the poorest.

Normally, the SVI value varies between 0 and 1 as it is the probability of the greenness density. From Table S4 to Table S6, very poor (DI1 $\leq .05)$ vegetation conditions were found in the Central and Southern regions. Very poor vegetation conditions were not found in the Northern region; however, the lowest SVI value in three timescales ranged from 0.06 to 0.07 . The greenness density of vegetation in the three regions between 2004 and 2006 was less severe than previous drought events. For DI2, the values of the three regions for the three timescales were slightly different. The DI showed that the Northern region had better vegetation conditions than the Central and Southern regions.

The poor vegetation conditions based on SVI may have been caused either by flood or drought. The conditions from 1988 to 1989, 1992 to 1994, 1998 to 1999 and 2004 to 2006 were believed to be due to drought as the low SVI values in these periods match the negative value of the SPI. The poor vegetation conditions from 1999 to 2001 were possibly 
caused by floods as positive SPI values were found in this period. Similarly, in a recent study, Ly et al. [39] reported that a greatest flood in 2000 occurred in Lower Mekong River.

\subsubsection{Impact of Drought on Cropping Pattern by SVI}

Figure S5 and Figure S6 show graphs for March, July, and November in relation to SVI3 and SVI6, respectively, in order to assess the greenness density of vegetation during the cropping period. The SVI3 indicated that poor vegetation conditions were found in the three selected months in 1994 and 2000, March in 1989, 1992, 1993 and 2004, July in 1993 and November in 1988. The ED rice varieties in the three selected months experienced low greenness density, but it occurred more frequently in March. It can be caused by the fact that ED1 is planted during the dry season and generally cultivated in areas located next to irrigation schemes or water resources.

The analysis of LD and MD rice varieties was considered in November since they are grown once a year and ripened during November. The SVI6 indicated that poor and very poor greenness density of LD and MD rice varieties were found in 1988, 1993, 1994 and 2000. Later, the poor and very poor greenness density did not occur from 2001 to 2008; however, the SVI value was below zero in 2005 and 2006. In short, the three types of rice varieties were badly damaged in 1988, 1993, 1994 and 2000. Moreover, ED1 had worse greenness density than other rice varieties.

\subsection{Drought distribution}

The distribution of droughts and vegetation greenness density over the Baribo basin is shown in Figure 4 and Figure 5, respectively. It should be noted that the agricultural area particularly is distributed in the eastern part of the Northern and Central regions and almost the entire Southern region[25]. Four DE were selected to develop the drought map of SPI and SVI at 3, 6 and 12 month timescales. The selected DE were in the month in which the SPI captured at least a severe drought $(S P I \leq-1.5)$ or SVI captured a very poor condition of vegetation (SVI $\leq 0.05)$. Our four selected DE were in November 1993, April 1994, August 2000 and November 2004. The description of the drought distribution over the entire Baribo basin is as follows:

The drought distribution map of SPI over the Baribo basin is illustrated in Error! Reference source not found.5. In November 1993 and April 1994, the drought was found in a large area of the Northern and Central regions. Besides, the Southern region mostly covered by a slight drought $(0<$ SPI $<-1)$ while a moderate drought occurred only in the northern part of this region in November 1993 and April 1994. Later in August 2000, the entire Baribo basin distributed by high rainfall except for the eastern part of the basin which is the low-lying region of the Tonle Sap Great Lake. In November 2004, the three timescales showed that the drought mainly occurred in the middle of the basin.

Error! Reference source not found.6 shows the map of vegetation conditions over the entire basin, based upon the SVI values at timescales of interest. The greenness density of vegetation in the eastern part of the basin where it connects to the Tonle Sap Great Lake, was higher than the other part in November 1993. The poor and very poor vegetation distributed almost the entire basin in April 1994 and August 2000, whereas the Central region was the most severe. November 2004, poor vegetation was found mainly in the eastern part of the basin, low-lying region of the Tonle Sap Great Lake. In short, the results showed that the entire basin experienced both flood and drought; however, conditions in the Central region were the most severe. More importantly, the results of SPI and SVI support the view that the poor vegetation in 2000 was caused by floods. 

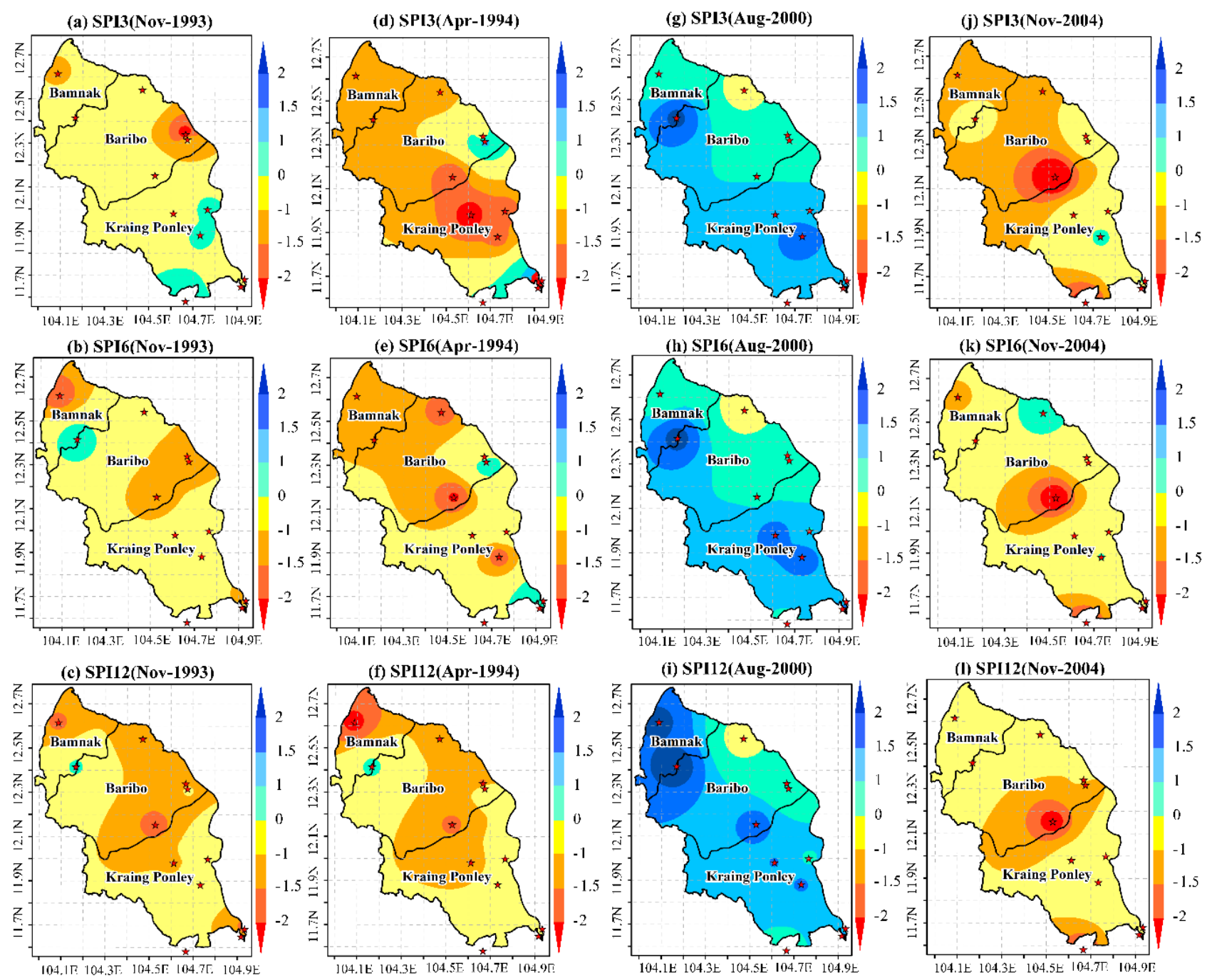

Figure 5. Drought map for the Baribo basin, based on SPI. 
(a) SVI3(Nov-1993)

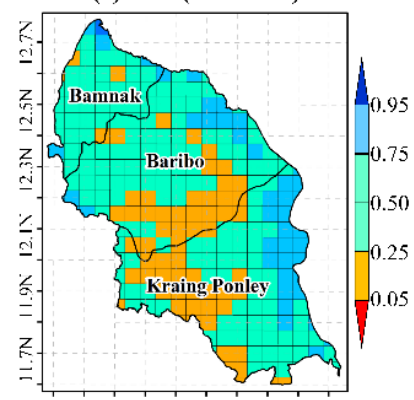

104.1E 104.3E 104.55 $104.75 \quad$ 104.95

(b) SVI6(Nov-1993)

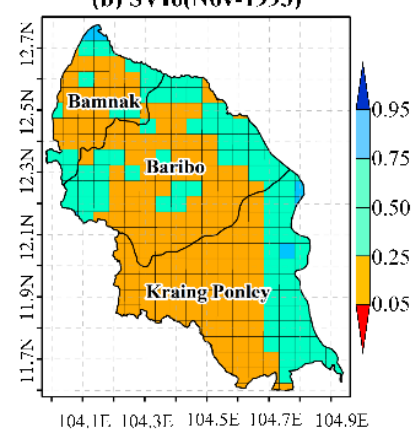

(c) SVI12(Nov-1993)

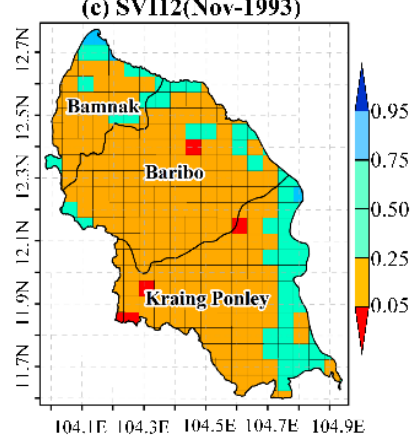

(d) SVI3(Apr-1994)

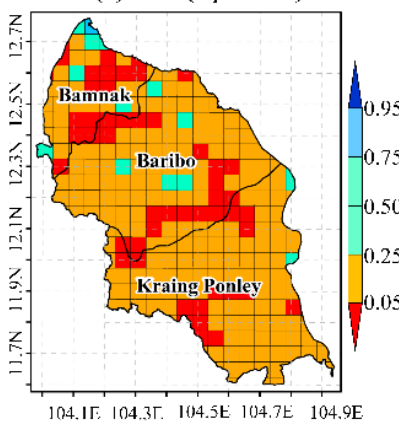

(c) SVI6(Apr-1994)

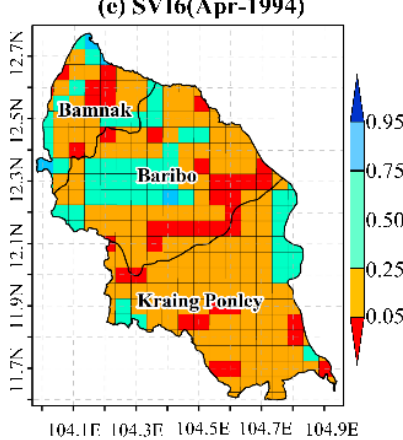

(f) SVI12(Apr-1994)

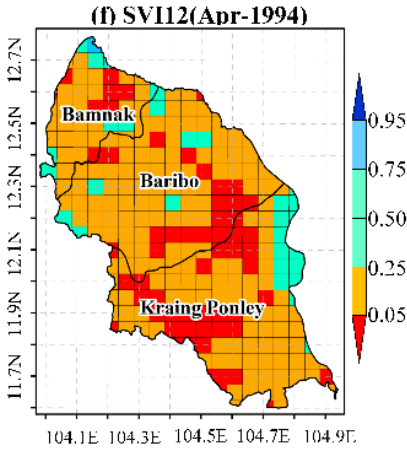

(g) SVI3(Aug-2000)

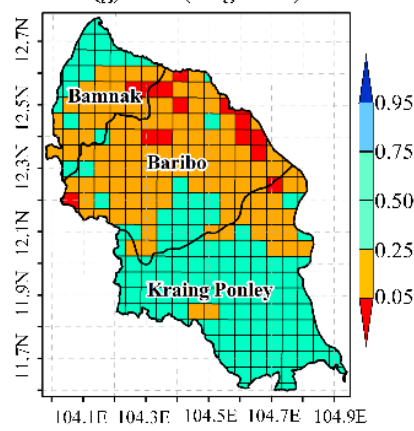

(h) SVI6(Aug-2000)

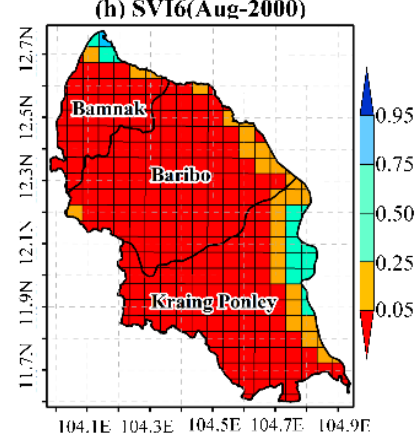

(i) SVI12(Aug-2000)

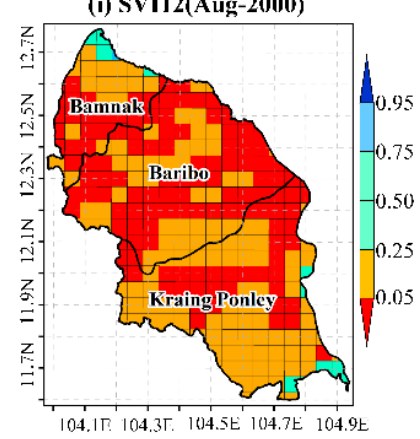

(j) SVI3(Jun-2005)

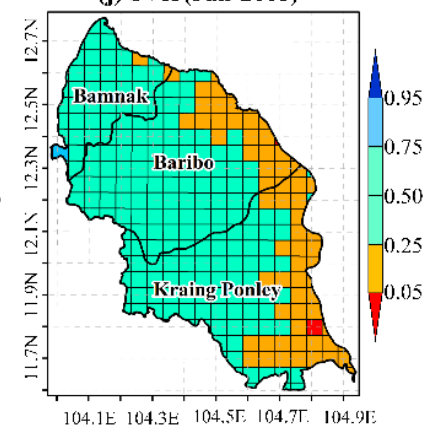

(k) SVI6(Jun-2005)

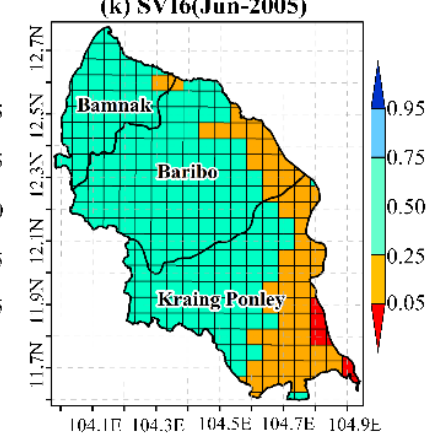

(I) SVI12(Jun-2005)

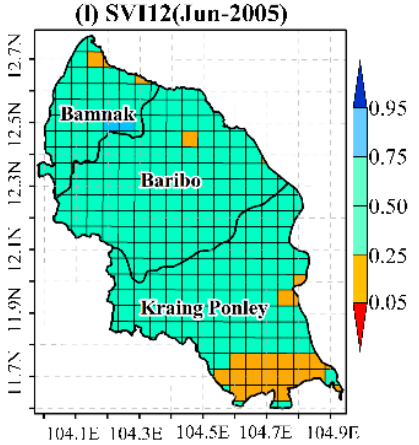

Figure 6. Drought map for the Baribo basin, based on SVI.

\section{Discussion}

SPI and SVI indices are capable of evaluating the impact of drought on agriculture since they can calculate at 3 and 6 month timescales, which comply with the cropping period of the three rice varieties. SPI shows the availability of rainfall for LD, MD, and ED rice varieties during the cropping period. The negative value of SPI shows that the rainfall is insufficient to fulfill the crop water requirement. The meteorological drought assessment using the SPI indicated that the Northern and Southern regions were droughtprone areas. The drought is found profoundly impact in the Northern region as the most frequent drought event (DE), the highest drought intensity (DI), and the most severe drought severity (DS) are found there at most timescale. In contrast, the Southern region experiences the longest length of drought duration (DD). SPI captured the drought from 1988 to 1989, 1993 to 1994, 1997 to 1998, and 2001 to 2006. Besides, the drought characteristics become more severe than the previous drought events from 2001 to 2006.

The assessment of the vegetation condition using the SVI shows that characteristics of vegetation in the Northern, Central and Southern regions have a high correlation. The SVI at 3 and 6 month timescales showed the greenness density of the crop during the growing period. If the SVI captured a poor greenness density $(\mathrm{SVI}<0.25)$ in a cropping period, it refers to an unhealthy or a failed crop during the cropping period. The poor condition of vegetation from 1988 to 1989, 1992 to 1994, 1999 to 2001 and 2004 to 2006 are believed to be due to drought as the low values of SVI in these periods match with the negative values of the SPI. The poor condition of vegetation between 1999 and 2001 was 
impacted by floods as a positive value of the SPI was found in this period. Our result showed that SVI was not able to detect the severe drought in 2004 which caused severe damage to the rice production. However, the drought distribution map in November 2004 (Error! Reference source not found.6) indicated that SVI showed a low greenness density only at the eastern part of the Baribo basin where is mostly covered by the rice paddy field. This is possibly caused by the extended of the agricultural region and irrigated area to the upstream under the development plan of RGC which cause an increasing of the greenness density. Generally, the low greenness density of the vegetation should occur after a temporary absence of rainfall; however, the results (Error! Reference source not found.5 and Error! Reference source not found.6) showed that the low SVI value occurred before the low value of SPI. It can be explained by considering the cropping pattern. There are several weeks of the post-harvesting period (Figure 2) after harvesting rice production or before growing new crops.

This section aims to indicate the impact of drought on food security. Figure 7 illustrates the annual yield, average annual yield and damaged area of rice from 1994 to 2012 (missing data in 1996, 2007 and 2010) in the Kampong Speu province, partly covers the Baribo basin (Figure 1). The data obtained from the Cambodian Ministry of Agriculture, Forestry and Fisheries (MAFF) were employed to indicate the relationship of drought with rice yield and estimates of damaged areas. Error! Reference source not found.7 shows the annual average rice yield was approximately $2 \mathrm{t} / \mathrm{ha}$. The rice yield between 1994 and 2008 was regularly lower than the annual average yield except in 1997 and 2006. However, rice yields significantly increased from 2009 to 2012, varying between 2.4 and $3.14 \mathrm{t} / \mathrm{ha}$. The lowest rice yield was in 2008 (1.19 t/ha) follow by 1994 (1.52 t/ha) and 2004 $(1.57 \mathrm{t} / \mathrm{ha})$. For the damaged areas, the data reveal that the drought impacted about $46 \%$ of the total rice paddy fields in 2004 and about 18\% in 1994, 1997 and 1998. The drought also occurred in 1995, 2002 and 2006, but the impacted area was lower than $6 \%$. The data show that the lowest annual rice yield in 2008 was not caused by drought as no evidence of drought damaged areas was found. Rice production was significantly impacted by drought in 1994, 1997, 1998 and 2004, while the heaviest damage was sustained in 2004.

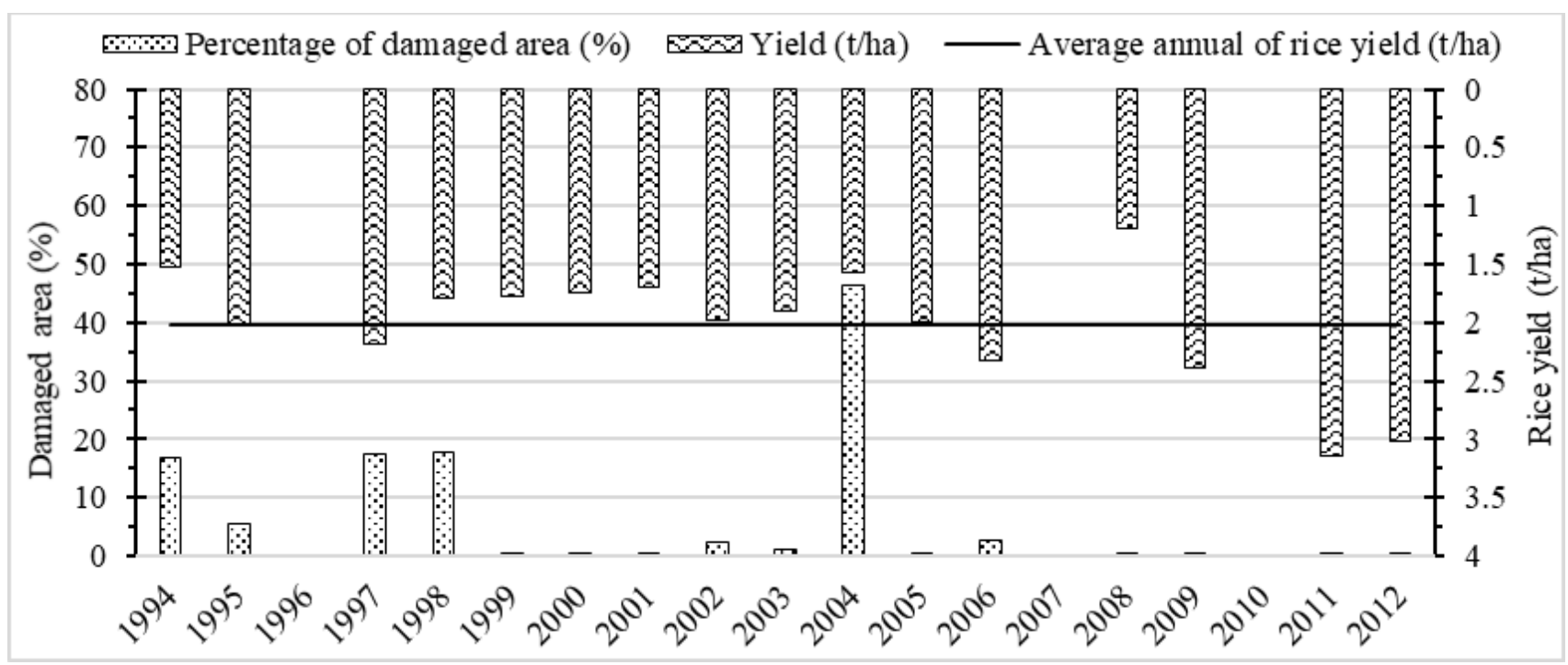

Figure 7. Area damaged and rice estimate yields in Kompong Speu province (reproduced with permission from Chhinh and Millington [19])

The results from SPI captured different drought intensity and severity in 1994, 1997, 1998 and 2004; however, the rice yield was slightly different, approximately $1.5 \mathrm{t} / \mathrm{ha}$. It appears that drought intensity and severity had a less significant impact on rice yield than drought duration. Drought duration had a higher correlation with the damage to rice production than other drought characteristics. SPI showed that the drought duration 
from 1993 to 1994 and 1997 to 1998 was significantly shorter than from 2002 to 2006 . At the same time, the area impacted by drought in each of the years 1994, 1997 and 1998 was about $18 \%$ while it was about $46 \%$ in 2004 . SVI identified poor greenness density in 1993 , 1994, 1997 and 1998; however, SVI showed slightly poor greenness density between 2002 and 2006.

\section{Conclusions}

SPI and SVI performed well in evaluating the meteorological and agriculture droughts in this study. These indices indicate that the Baribo basin was severely impacted by drought. Based on the analysis of drought using SPI and SVI, the highest intensity and severity of drought in the Baribo basin occurred in 1993 and 1994, while this area was subject to severe flooding in 2000. Drought duration significantly increased between 2001 and 2006. Droughts are a major hazard in Cambodia, resulting in food insecurity. The most severe damage to rice production was in 2004 , affecting about $46 \%$ of the total cultivated area. The DI and DS had a less significant impact on the rice yield, while drought duration had a strong relationship with the area of rice damaged. Rice production significantly increased between 2005 and 2012, indicating the effectiveness of the RGC's "Rectangular Strategies" for improving agricultural management, along with adaptations to increase milled rice exports to the global rice market and to support the food security policy.

Supplementary Materials: The following supporting information are listed below:

\section{List of Figures}

Figure S1. The fit of Gamma distribution to monthly rainfall of Greater Baribo basin.

Figure S2. Definition sketch of the Theory of Runs.

Figure S3. SPI3 in March, July and November between 1985 and 2008.

Figure S4. SPI6 in March, July and November between 1985 and 2008.

Figure S5. SVI3 in March, July and November between 1985 to 2008.

Figure S6. SVI6 in March, July and November between 1985 to 2008.

\section{List of Tables}

Table S1. Drought Characteristics of the three sub-basins for SPI3.

Table S2. Drought Characteristics of the three sub-basins for SPI6.

Table S3. Drought Characteristics of the three sub-basins for SPI12.

Table S4. Drought Characteristics of the three sub-basins for SVI3.

Table S5. Drought Characteristics of the three sub-basins for SVI6.

Table S6. Drought Characteristics of the three sub-basins for SVI12. 


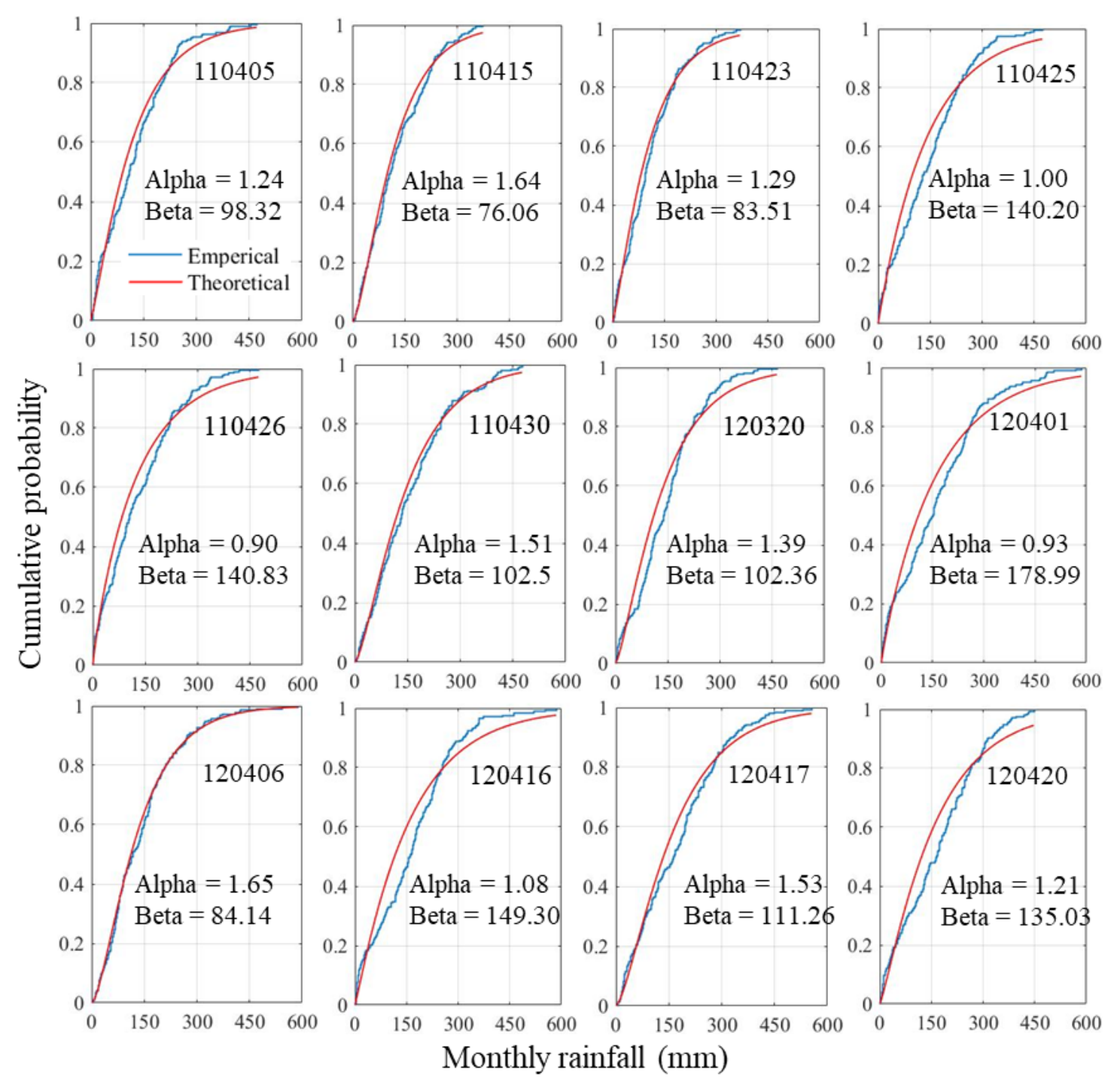

Figure S1. The fit of Gamma distribution to monthly rainfall of Greater Baribo basin.

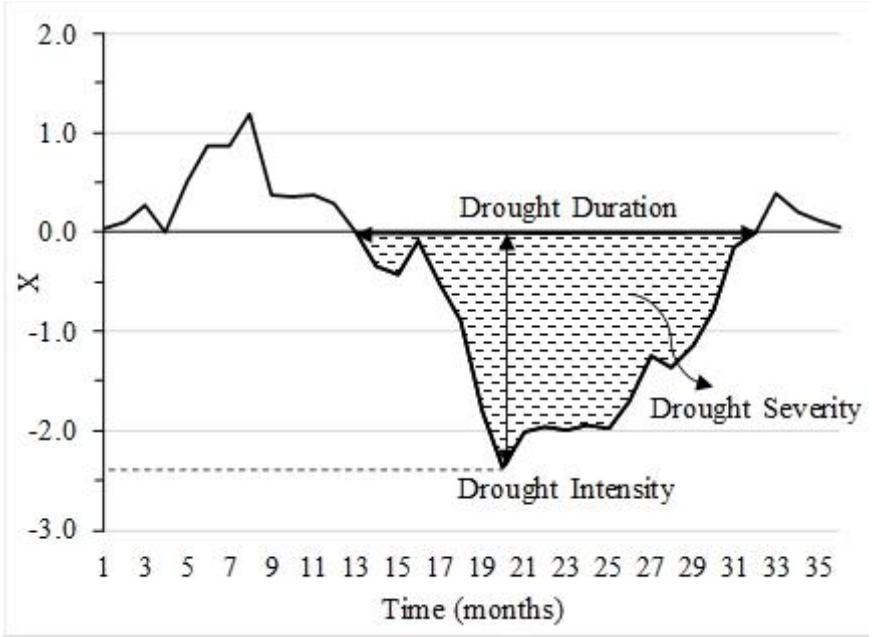

Figure S2. Definition sketch of the Theory of Runs. 


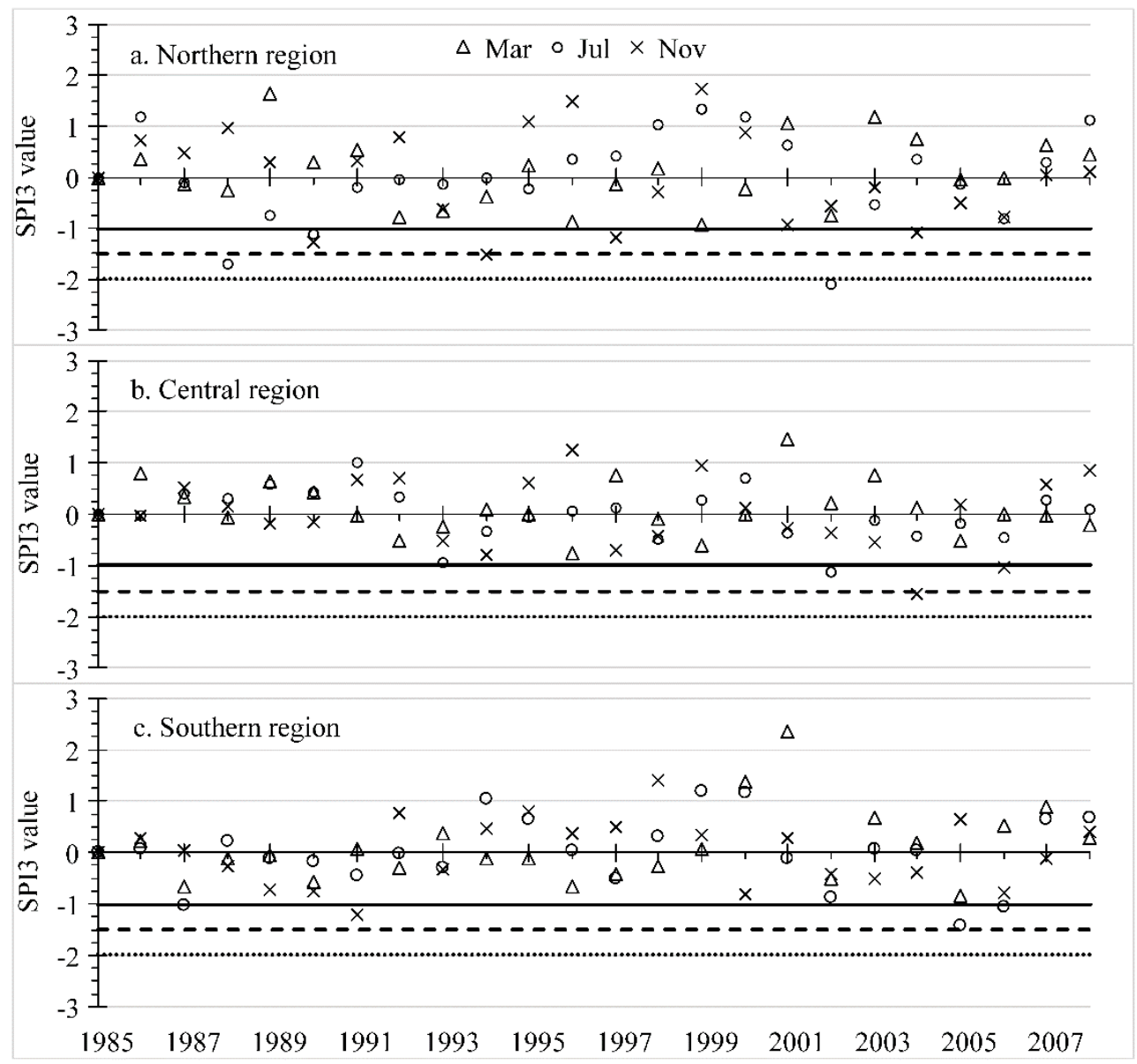

Figure S3. SPI3 in March, July and November between 1985 and 2008. 


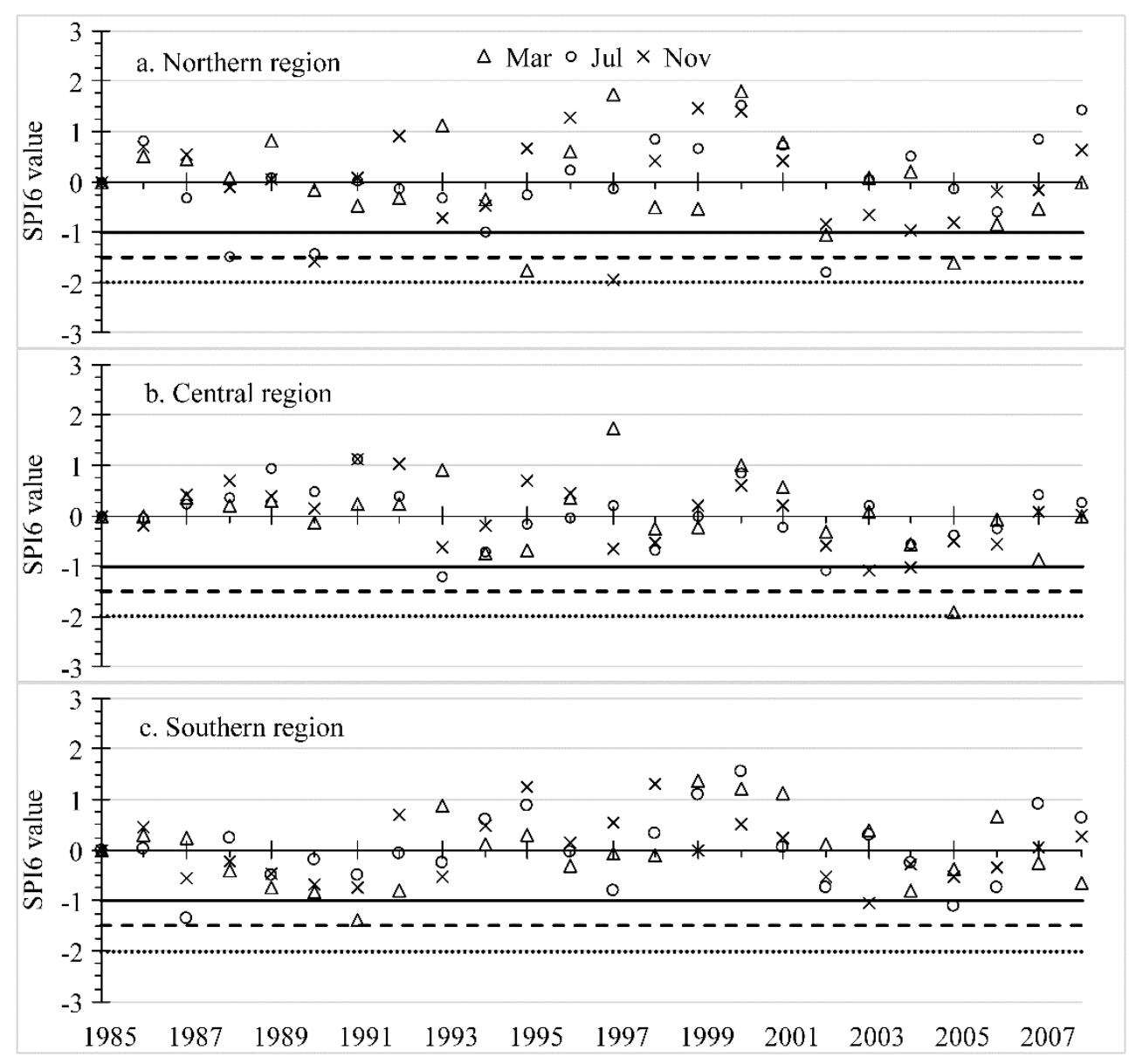

Figure S4. SPI6 in March, July and November between 1985 and 2008. 


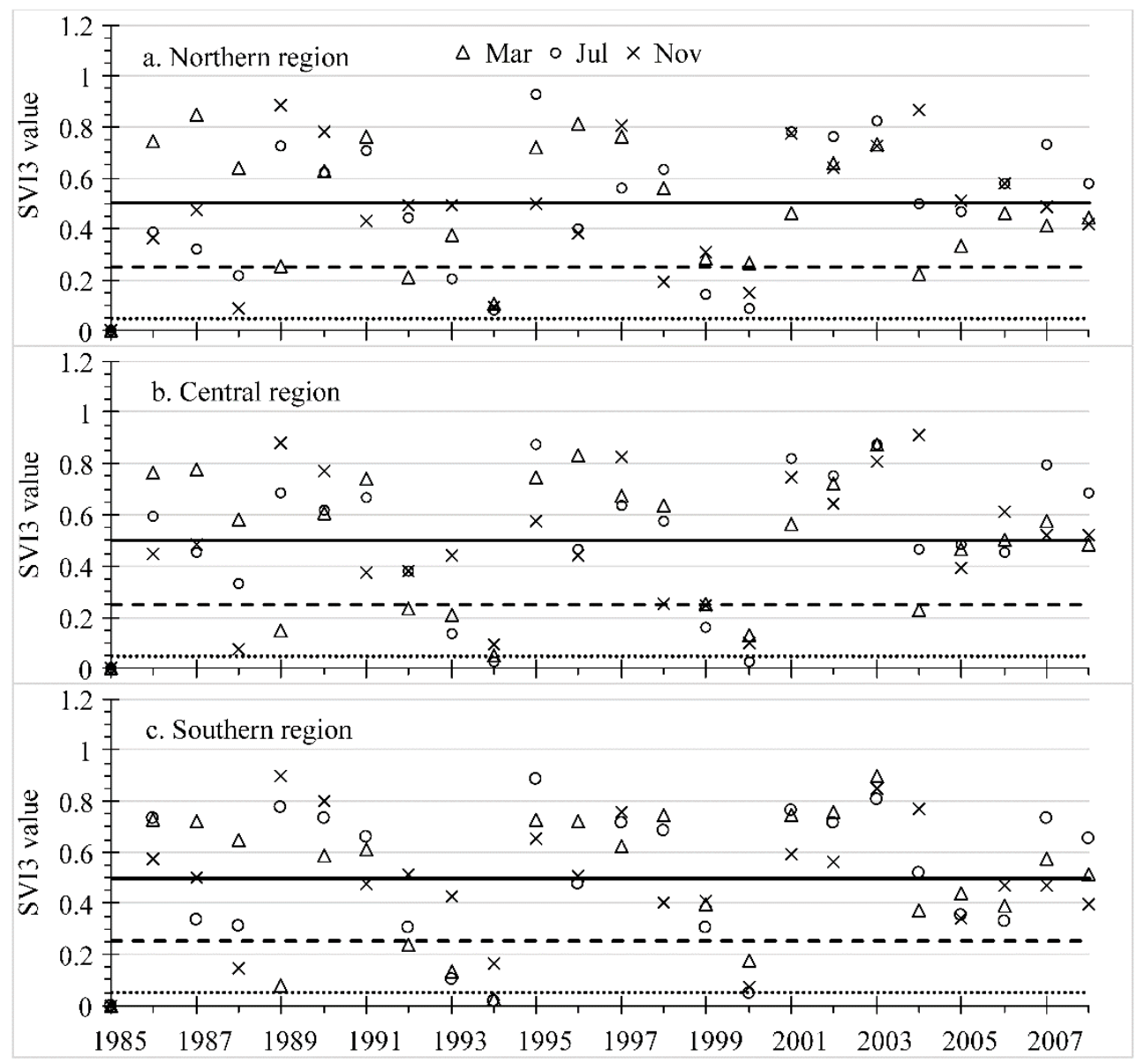

Figure S5. SVI3 in March, July and November between 1985 to 2008. 


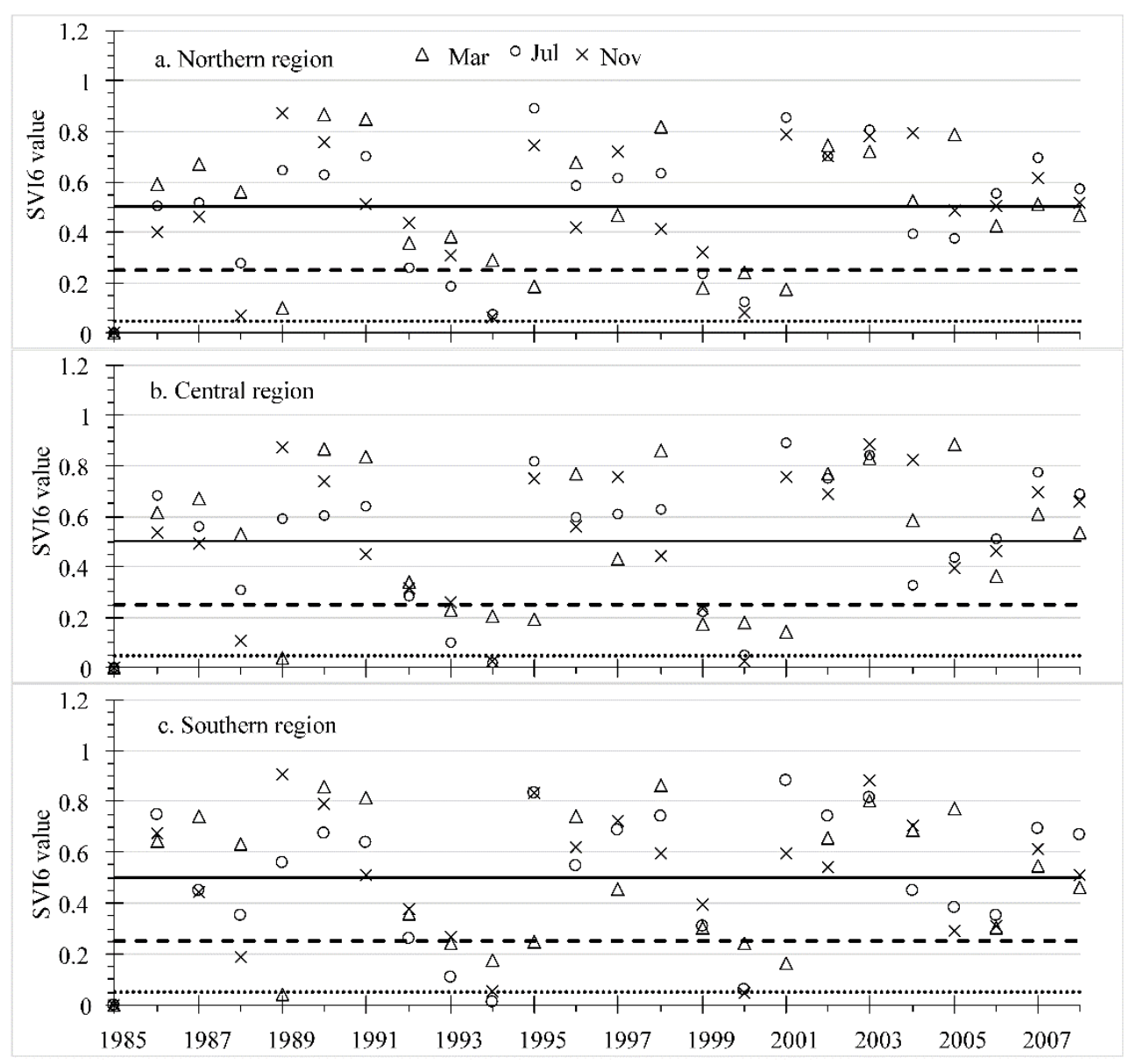

Figure S6. SVI6 in March, July and November between 1985 to 2008. 
Table S1. Drought Characteristics of the three sub-basins for SPI3.

\begin{tabular}{|c|c|c|c|c|c|}
\hline Region & DE & DD & DS & DI1 & DI2 \\
\hline \multirow{11}{*}{ Northern } & 1. Mar-1987 to Jul-1987 & 5 & 2.27 & 1.03 & 0.45 \\
\hline & 2. May-1988 to Oct-1988 & 6 & 5.94 & 1.70 & 0.99 \\
\hline & 3. Apr-1990 to Dec-1990 & 9 & 12.01 & 2.44 & 1.33 \\
\hline & 4. Mar-1994 to Jul-1994 & 5 & 2.91 & 1.25 & 0.58 \\
\hline & 5. Oct-1994 to Feb-1995 & 5 & 4.39 & 1.83 & 0.88 \\
\hline & 6. Mar-1997 to Apr-1997 & 2 & 1.20 & 1.05 & 0.60 \\
\hline & 7. Aug-1997 to Dec-1997 & 5 & 7.29 & 2.15 & 1.46 \\
\hline & 8. Sep-1998 to Apr-1999 & 8 & 3.26 & 1.25 & 0.41 \\
\hline & 9. May-2002 to Jan-2003 & 9 & 6.41 & 2.10 & 0.71 \\
\hline & 10. Oct-2005 to Mar-2006 & 6 & 6.37 & 1.85 & 1.06 \\
\hline & 11. Nov-2006 to Jan-2007 & 3 & 2.47 & 1.02 & 0.82 \\
\hline \multirow{7}{*}{ Central } & 1. Mar-1993 to Sep-1993 & 7 & 4.82 & 1.27 & 0.69 \\
\hline & 2. Apr-1994 to Jul-1994 & 4 & 3.10 & 1.22 & 0.78 \\
\hline & 3. Mar-1998 to Nov-1998 & 9 & 5.73 & 1.13 & 0.64 \\
\hline & 4. Apr-2002 to Dec-2002 & 9 & 5.43 & 2.10 & 0.60 \\
\hline & 5. Jun-2003 to Feb 2004 & 9 & 5.15 & 1.08 & 0.57 \\
\hline & 6. Mar-2004 to Apr 2005 & 13 & 10.77 & 1.78 & $\mathbf{0 . 8 3}$ \\
\hline & 7. Oct-2006 to Jan 2007 & 4 & 3.03 & 1.03 & 0.76 \\
\hline \multirow{9}{*}{ Southern } & 1. Feb-1987 to Oct-1987 & 9 & 6.77 & 1.22 & 0.75 \\
\hline & 2. Mar-1989 to May-1990 & 15 & 7.62 & 1.43 & 0.51 \\
\hline & 3. Jul-1990 to Feb-1991 & 8 & 4.45 & 1.50 & 0.56 \\
\hline & 4. Apr-1991 to Jan-1992 & 10 & 6.49 & 1.20 & 0.65 \\
\hline & 5. Mar-1994 to May-1994 & 3 & 2.37 & 1.82 & 0.79 \\
\hline & 6. Aug-1999 to Oct 1999 & 3 & 1.47 & 1.10 & 0.49 \\
\hline & 7. Aug-2003 to Feb-2004 & 7 & 4.84 & 1.07 & 0.69 \\
\hline & 8. Jun-2005 to Sep 2005 & 4 & 4.38 & 1.71 & 1.10 \\
\hline & 9. May 2006 to Jul 2006 & 3 & 2.78 & 1.05 & 0.93 \\
\hline
\end{tabular}


Table S2. Drought Characteristics of the three sub-basins for SPI6.

\begin{tabular}{|cccccc|}
\hline Region & DE & DD & DS & DI1 & DI2 \\
\hline \multirow{5}{*}{ Northern } & 1. May-1988 to Dec 1998 & 8 & 7.43 & 1.94 & 0.93 \\
& 2. Mar-1990 to Mar-1991 & 13 & $\mathbf{1 7 . 8 3}$ & $\mathbf{2 . 4 4}$ & $\mathbf{1 . 3 7}$ \\
& 3. Apr-1992 to Jun-1992 & 3 & 1.99 & 1.26 & 0.66 \\
& 4. Apr-1993 to Aug-1994 & $\mathbf{1 7}$ & 8.82 & 1.09 & 0.52 \\
& 5. Oct-1994 to Sep-1995 & 12 & 7.70 & 1.76 & 0.64 \\
& 6. Jun-1997 to Mar-1998 & 10 & 10.06 & 1.96 & 1.01 \\
& 7. Dec-1998 to Apr-1999 & 5 & 3.12 & 1.51 & 0.62 \\
& 8. Feb-2002 to Feb-2003 & 13 & 12.99 & 1.80 & 1.00 \\
& 9. Aug-2003 to Feb-2004 & 7 & 4.32 & 1.03 & 0.62 \\
& 10. Sep-2004 to Jul-2006 & 14 & 7.62 & 1.65 & 0.54 \\
\hline \multirow{5}{*}{ Central } & 1. Apr-1993 to Sep-1995 & $\mathbf{3 0}$ & 16.35 & 1.39 & 0.55 \\
& 2. Feb-2002 to Feb-2003 & 13 & 8.80 & 1.19 & 0.68 \\
3. Aug-2003 to Jan-2006 & $\mathbf{3 0}$ & $\mathbf{2 3 . 2 6}$ & $\mathbf{1 . 9 2}$ & $\mathbf{0 . 7 8}$ \\
\hline \multirow{5}{*}{ Southern } & 1. Apr-1987 to Apr-1988 & 13 & 8.35 & 1.43 & 0.64 \\
& 2. Oct-1988 to Aug-1992 & $\mathbf{4 7}$ & $\mathbf{2 8 . 1 9}$ & 1.39 & 0.60 \\
& 3. May-1993 to Feb-1994 & 10 & 5.91 & 1.07 & 0.59 \\
& 4. Apr-2002 to Feb-2003 & 11 & 5.91 & 1.02 & 0.54 \\
& 5. Aug-2003 to May-2004 & 10 & 7.86 & 1.18 & $\mathbf{0 . 7 9}$ \\
6. May-2005 to Dec-2005 & 8 & 5.77 & $\mathbf{1 . 5 4}$ & 0.72 \\
\hline
\end{tabular}

Table S3. Drought Characteristics of the three sub-basins for SPI12.

\begin{tabular}{|cccccc|}
\hline Region & DE & DD & DS & DI1 & DI2 \\
\hline \multirow{3}{*}{ Northern } & 1. Apr-1990 to Sep-1991 & 18 & 22.76 & $\mathbf{2 . 3 8}$ & $\mathbf{1 . 2 6}$ \\
& 2. Oct-1993 to Sep-1992 & 24 & 18.58 & 1.29 & 0.77 \\
& 3. Oct-1997 to Aug-1998 & 11 & 11.24 & 1.76 & 1.02 \\
& 4. Jun-2002 to Apr-2007 & $\mathbf{5 9}$ & $\mathbf{4 3 . 0 3}$ & 1.65 & 0.73 \\
\hline \multirow{3}{*}{ Central } & 1. Aug-1993 to Sep-1995 & 26 & 14.73 & 1.09 & 0.57 \\
& 2. Nov-1997 to Sep-1999 & 23 & 12.67 & 1.04 & 0.55 \\
& 3. May-2002 to Jul-2006 & $\mathbf{5 1}$ & $\mathbf{3 6 . 6 3}$ & $\mathbf{1 . 1 9}$ & $\mathbf{0 . 7 2}$ \\
\hline \multirow{2}{*}{ Southern } & 1. Oct-1988 to Sep-1992 & 48 & $\mathbf{3 1 . 4 1}$ & 1.37 & $\mathbf{0 . 6 5}$ \\
& 2. May-2002 to Jul-2006 & $\mathbf{5 1}$ & 29.10 & $\mathbf{1 . 3 8}$ & 0.57 \\
\hline
\end{tabular}


Table S4. Drought characteristics of the three sub-basins for SVI3.

\begin{tabular}{|llcccc|}
\hline Region & \multicolumn{1}{c}{ DE } & DD & DS & DI1 & DI2 \\
\hline \multirow{5}{*}{ Northern } & 1. Apr-1988 to Apr-1989 & 13 & 2.91 & 0.08 & 0.22 \\
& 2. Sep-1991 to Jan-1993 & $\mathbf{2 3}$ & 7.26 & 0.15 & 0.32 \\
& 3. Jan-1994 to Feb-1995 & 14 & 2.15 & 0.08 & 0.15 \\
& 4. Oct-1998 to Mar-1999 & 6 & 1.50 & 0.12 & 0.25 \\
& 5. May-1998 to Mar-2001 & $\mathbf{2 3}$ & 5.03 & 0.06 & 0.22 \\
& 6. Feb-2004 to Jul-2004 & 6 & 2.20 & 0.22 & 0.37 \\
\hline \multirow{5}{*}{ Central } & 1. Apr-1988 to May-1989 & 14 & 3.41 & $\mathbf{0 . 0 4}$ & 0.24 \\
& 2. Sep-1991 to Feb-1995 & $\mathbf{4 2}$ & 9.25 & $\mathbf{0 . 0 3}$ & 0.22 \\
& 3. Nov-1998 to Feb-2001 & 28 & 5.04 & $\mathbf{0 . 0 2}$ & 0.18 \\
& 4. Feb-2004 to Jul-2004 & 6 & 1.97 & 0.20 & 0.33 \\
& 5. Jul-2006 to Oct-2006 & 4 & 1.30 & 0.20 & 0.33 \\
\hline \multirow{5}{*}{ Southern } & 1. Apr-1988 to May-1989 & 14 & 3.57 & $\mathbf{0 . 0 4}$ & 0.26 \\
& 2. Sep-1991 to Oct-1992 & 14 & 4.66 & 0.23 & 0.33 \\
& 3. Nov-1992 to Feb-1995 & 27 & 5.00 & $\mathbf{0 . 0 2}$ & 0.19 \\
& 4. Nov-1998 to Feb-2001 & $\mathbf{2 8}$ & 6.70 & $\mathbf{0 . 0 5}$ & 0.24 \\
& 5. Mar-2005 to Nov-2006 & 21 & 6.81 & 0.13 & 0.32 \\
\hline
\end{tabular}

Table S5. Drought Characteristics of the three sub-basins for SVI6.

\begin{tabular}{|clcccc|}
\hline \multicolumn{1}{c}{ Region } & \multicolumn{1}{c}{ DE } & DD & DS & DI1 & DI2 \\
\hline \multirow{3}{*}{ Northern } & 1. Jun-1988 to Jun-1989 & 13 & 2.52 & 0.07 & 0.19 \\
& 2. Dec-1992 to May-1995 & $\mathbf{4 2}$ & 10.85 & 0.07 & 0.26 \\
& 3. Nov-1998 to May-2001 & 31 & 6.57 & 0.08 & 0.21 \\
\hline \multirow{3}{*}{ Central } & 1. Jun-1988 to Jun-1989 & 13 & 2.46 & $\mathbf{0 . 0 4}$ & 0.19 \\
& 2. Sep-1992 to May-1995 & $\mathbf{4 5}$ & 9.73 & $\mathbf{0 . 0 2}$ & 0.22 \\
& 3. Nov-1998 to Apr-2001 & 30 & 5.1 & $\mathbf{0 . 0 2}$ & 0.17 \\
\hline \multirow{5}{*}{ Southern } & 1. Jun-1988 to Jun-1989 & 13 & 2.83 & $\mathbf{0 . 0 4}$ & 0.22 \\
& 2. Dec-1992 to Apr-1995 & $\mathbf{4 1}$ & 8.69 & $\mathbf{0 . 0 1}$ & 0.21 \\
& 3. Jan-1999 to Apr-2001 & 28 & 6.09 & $\mathbf{0 . 0 4}$ & 0.22 \\
& 4. Jun-2005 to Feb-2007 & 21 & 6.35 & 0.18 & 0.30 \\
\hline
\end{tabular}


Table S6. Drought Characteristics of the three sub-basins for SVI12.

\begin{tabular}{|clcccc|}
\hline \multicolumn{1}{c}{ Region } & \multicolumn{1}{c}{ DE } & DD & DS & DI1 & DI2 \\
\hline \multirow{3}{*}{ Northern } & 1. Jun-1988 to Oct-1989 & 17 & 3.93 & 0.10 & 0.23 \\
& 2. Feb-1992 to Aug-1995 & $\mathbf{4 3}$ & 10.47 & 0.06 & 0.24 \\
& 3. Dec-1998 to Aug-2001 & 33 & 6.78 & 0.09 & 0.21 \\
\hline \multirow{3}{*}{ Central } & 1. Jun-1988 to Oct-1989 & 17 & 3.81 & 0.08 & 0.22 \\
& 2. Jan-1992 to Sep-1993 & $\mathbf{4 5}$ & 8.42 & $\mathbf{0 . 0 2}$ & 0.19 \\
& 3. Dec-1998 to Sep-2001 & 34 & 6.16 & $\mathbf{0 . 0 3}$ & 0.18 \\
\hline \multirow{5}{*}{ Southern } & 1. Aug-1988 to Oct-1989 & 15 & 3.55 & 0.10 & 0.24 \\
& 2. Jan-1992 to Jul-1995 & $\mathbf{4 3}$ & 8.63 & $\mathbf{0 . 0 3}$ & 0.20 \\
& 3. Apr-1999 to Sep-2001 & 30 & 6.65 & $\mathbf{0 . 0 4}$ & 0.22 \\
& 4. Oct-2005 to Jul-2007 & 22 & 6.68 & 0.19 & 0.30 \\
\hline
\end{tabular}

Author Contributions: All of the authors listed contributed to the manuscript production. Kimhuy Sok contributed to data analysis and drafted the manuscript. Supattra Visessri designed the research methodology and manuscript structure. Sokchhay Heng contributed to the acquisition of the data and fact-checking. All authors reviewed, edited and approved the manuscript.

Funding: This research was funded by Collaborative Research Program (CR) under the ASEAN University Network/Southeast Asia Engineering Education Development Network (AUN/SEEDNet project) of Japan International Cooperation Agency (JICA).

Data Availability Statement: Due to its proprietary nature, rainfall data used in this study cannot be made openly available. However, the rainfall data can be requested from the Ministry of Water Resources and Meteorology (MOWRAM). The NDVI data used in this study were downloaded from (website link). Further documentation about data processing is available at [web link to the documentation].

Acknowledgments: We would like to express our sincere thanks to MOWRAM and NOAA for providing the data used in this study. The authors also gratefully acknowledge financial support from Asean University Network/Southeast Asia Engineering Education Development Network (AUN/SEED-Net).

Conflicts of Interest: None of the authors are aware of any conflict of interest involving this study or the submitted article. 


\section{References}

1. Müller, B.; Hoffmann, F.; Heckelei, T.; Müller, C.; Hertel, T. W.; Polhill, J. G.; van Wijk, M.; Achterbosch, T.; Alexander, P.; Brown, C.; Kreuer, D.; Ewert, F.; Ge, J.; Millington, J. D. A.; Seppelt, R.; Verburg, P. H.; Webber, H., Modelling food security: Bridging the gap between the micro and the macro scale. Global Environmental Change 2020, 63, 102085.

2. Namany, S.; Govindan, R.; Alfagih, L.; McKay, G.; Al-Ansari, T., Sustainable food security decision-making: An agent-based modelling approach. Journal of Cleaner Production 2020, 255, 120296.

3. Amadou, T.; Gatien N, F.; Mamoutou, K.; Georges, S.; Alassane, B. A.; François, A.; Michel, G.; Benjamin, S., Farmers' perception and adaptation strategies to climate change in central Mali. Weather, Climate, and Society 2021.

4. Malone, E. L., Climate Change and National Security. Weather, Climate, and Society 2013, 5 (1), 93-95.

5. Culas, R. J.; Tek, K., Food security in Cambodia: trends and policy objectives. International Journal of Development Issues 2016, $15(3), 306-327$.

6. Misselhorn, A.; Aggarwal, P.; Ericksen, P.; Gregory, P.; Horn-Phathanothai, L.; Ingram, J.; Wiebe, K., A vision for attaining food security. Current opinion in environmental sustainability 2012, 4 (1), 7-17.

7. Vermeulen, S. J.; Aggarwal, P. K.; Ainslie, A.; Angelone, C.; Campbell, B. M.; Challinor, A. J.; Hansen, J. W.; Ingram, J.; Jarvis, A.; Kristjanson, P., Options for support to agriculture and food security under climate change. Environmental Science E Policy 2012, $15(1), 136-144$.

8. Conijn, J. G.; Bindraban, P. S.; Schröder, J. J.; Jongschaap, R. E. E., Can our global food system meet food demand within planetary boundaries? Agriculture, Ecosystems $\mathcal{E}$ Environment 2018, 251, 244-256.

9. Mc Carthy, U.; Uysal, I.; Badia-Melis, R.; Mercier, S.; O'Donnell, C.; Ktenioudaki, A., Global food security - Issues, challenges and technological solutions. Trends in Food Science E Technology 2018, 77, 11-20.

10. D'Odorico, P.; Davis, K. F.; Rosa, L.; Carr, J. A.; Chiarelli, D.; Dell'Angelo, J.; Gephart, J.; MacDonald, G. K.; Seekell, D. A.; Suweis, S.; Rulli, M. C., The Global Food-Energy-Water Nexus. Reviews of Geophysics 2018,56 (3), $456-531$.

11. Tian, X.; Engel, B. A.; Qian, H.; Hua, E.; Sun, S.; Wang, Y., Will reaching the maximum achievable yield potential meet future global food demand? Journal of Cleaner Production 2021, 294, 126285.

12. Hameed, M.; Ahmadalipour, A.; Moradkhani, H., Drought and food security in the middle east: An analytical framework. Agricultural and Forest Meteorology 2020, 281, 107816.

13. Jones, E. C.; Ong, C.; Haynes, J., Disaster-Related Food Security and Past General Governance Strategies in a Worldwide Sample. Weather, Climate, and Society 2021, 14 (1), 3-18.

14. Cai, J.; Ung, L.; Setboonsarng, S.; Leung, P. Rice Contract Farming in Cambodia: Empowering Farmers to Move Beyond the Contract Toward Independence; Asian Development Bank Institute: Tokyo, 2008.

15. RGC Rectangular Strategy for Growth, Employment, Equity and Efficiency: Building the foundation Toward Realizing the Cambodia Vision 2050; Royal Government of Cambodia (RGC): Phnom Penh, Cambodia, September $2018,2018$.

16. Bansok, R.; Chhun, C.; Phirun, N., Agricultural development and climate change: the case of Cambodia. CDRI: 2011.

17. Yihui, D., The variability of the Asian summer monsoon. Journal of the Meteorological Society of Japan. Ser. II 2007, 85, 21-54.

18. Wilhite, D. A., Drought. In Encyclopedia of World Climatology, Oliver, J. E., Ed. Springer Netherlands: Dordrecht, 2005; pp 338-341.

19. Chhinh, N.; Millington, A., Drought monitoring for rice production in Cambodia. Climate 2015, 3 (4), 792-811.

20. Yihdego, Y.; Vaheddoost, B.; Al-Weshah, R. A., Drought indices and indicators revisited. Arabian Journal of Geosciences 2019, $12(3), 69$.

21. Wang, J.; Rong, G.; Li, K.; Zhang, J., Analysis of Drought Characteristics in Northern Shaanxi Based on Copula Function. Water 2021, 13 (11).

Wilhite, D. A.; Glantz, M. H., Understanding: the drought phenomenon: the role of definitions. Water international 1985, 10 (3), 111-120. 
23. WMO; GWP, Handbook of drought indicators and indices. World Meteorological Organization (WMO) and Global Water Partnership (GWP): 2016.

24. Hayes, M. J., Drought indices. Wiley Online Library: National Drought Mitigation Center, 2006.

25. Sok, K.; Visessri, S.; Heng, S. In A Comparative Assessment of Meteorological Drought Indices for the Baribo Basin (Cambodia), Advances in Sustainable and Environmental Hydrology, Hydrogeology, Hydrochemistry and Water Resources, Cham, 2019//; Chaminé, H. I.; Barbieri, M.; Kisi, O.; Chen, M.; Merkel, B. J., Eds. Springer International Publishing: Cham, 2019; pp 9-12.

26. Arias, M. E.; Cochrane, T. A.; Norton, D.; Killeen, T. J.; Khon, P., The Flood Pulse as the Underlying Driver of Vegetation in the Largest Wetland and Fishery of the Mekong Basin. AMBIO 2013, 42 (7), 864-876.

27. MRC Planning atlas of the lower Mekong River basin; 2011.

28. Sok, K.; Visessri, S.; Heng, S., Meteorological Drought Assessment for the Baribo Basin in Cambodia. Internet Journal of Society for Social Management Systems 2017, 11 (1 sms17-2115), 146-157.

29. Laaha, G.; Blöschl, G., Low flow estimates from short stream flow records - a comparison of methods. Journal of Hydrology 2005, 306 (1), 264-286.

30. Jin, B.; Wu, Y.; Miao, B.; Wang, X. L.; Guo, P., Bayesian spatiotemporal modeling for blending in situ observations with satellite precipitation estimates. Journal of Geophysical Research: Atmospheres 2014, 119 (4), 1806-1819.

31. Hinge, G.; Mohamed, M. M.; Long, D.; Hamouda, M. A., Meta-Analysis in Using Satellite Precipitation Products for Drought Monitoring: Lessons Learnt and Way Forward. Remote Sensing 2021, 13 (21).

McKee, T. B.; Doesken, N. J.; Kleist, J. In The relationship of drought frequency and duration to time scales, Proceedings of the 8th Conference on Applied Climatology, American Meteorological Society Boston, MA: 1993; pp 179-183.

33. Wilhite, D. A., Quantification of agricultural drought for effective drought mitigation and preparedness: Key issues and challenges. 2011.

34. Guo, H.; Bao, A.; Liu, T.; Ndayisaba, F.; He, D.; Kurban, A.; De Maeyer, P., Meteorological drought analysis in the Lower Mekong Basin (LMB) using satellite-based long-term CHIRPS product. Sustainability 2017, 9 (6), 901.

35. Peters, A. J.; Walter-Shea, E. A.; Ji, L.; Vina, A.; Hayes, M.; Svoboda, M. D., Drought monitoring with NDVI-based standardized vegetation index. Photogrammetric engineering and remote sensing 2002, 68 (1), 71-75.

36. Tian, F.; Brandt, M.; Liu, Y. Y.; Verger, A.; Tagesson, T.; Diouf, A. A.; Rasmussen, K.; Mbow, C.; Wang, Y.; Fensholt, R., Remote sensing of vegetation dynamics in drylands: Evaluating vegetation optical depth (VOD) using AVHRR NDVI and in situ green biomass data over West African Sahel. Remote Sensing of Environment 2016, 177, 265-276.

37. Yevjevich, V. M. An objective approach to definitions and investigations of continental hydrologic droughts; 1967.

38. Rahmat, S.; Jayasuriya, N. a.; Muhammed, B., Assessing droughts using meteorological drought indices in Victoria, Australia. Hydrology Research 2014, 46 (3), 463-476. 